\title{
O PAPEL DO GOVERNO E A PRÁTICA DO CONSUMO SUSTENTÁVEL: como esse stakeholder atua no setor elétrico?
}

\author{
1- Minelle Enéas da Silva* \\ Mestrando em Administração pela Universidade Federal de Pernambuco (UFPE), Brasil \\ minele.adm@gmail.com \\ http://lattes.cnpq.br/3329329091837689
}

\section{2- Carla R. Pasa Gómez}

Doutora em Engenharia de Produção pela Universidade Federal de Santa Catarina (UFSC), Brasil

Professora do Programa de Pós-Gradação em Administração da Universidade Federal de Pernambuco (PROPAD/UFPE), Brasil

carlapasagomez@gmail.com

http://lattes.cnpq.br/1964176230213353 


\section{O PAPEL DO GOVERNO E A PRÁTICA DO CONSUMO SUSTENTÁVEL: COMO ESSE STAKEHOLDER ATUA NO SETOR ELÉTRICO?}

\section{RESUMO}

As discussões que envolvem a perspectiva do desenvolvimento sustentável cada vez mais estão presentes no cotidiano da sociedade, ao se perceber a necessidade de uma reestruturação nas práticas até então adotadas. Nesse contexto, percebe-se que emergem aspectos como o consumo sustentável, o qual pode ser entendido como o padrão de consumo resultante de inter-relações entre atores sociais direcionados para o desenvolvimento sustentável (MICHAELIS, 2003; JACKSON, 2007; SILVA, 2010). De fato, com a atuação de diferentes atores necessita-se identificar como cada um se comporta. Assim, o presente trabalho objetiva-se a identificar qual o papel do governo no auxílio ao consumo sustentável, entendendo que esse deve estar envolvido com outros atores em um determinado setor econômico. Utiliza-se uma pesquisa exploratório-descritiva com abordagem qualitativa, conduzida sob a forma de um estudo de caso na Companhia Elétrica de Pernambuco (CELPE), que busca contribuir para o alcance de um consumo sustentável no setor. A partir de uma caracterização do setor e da análise do consumo sustentável, tornouse possível identificar o papel do governo nesse sentido, o qual envolve muitas vertentes que não necessariamente se restringem a regulamentação. Desse modo, percebe-se a originalidade e relevância do trabalho na discussão sobre a temática do consumo sustentável.

\section{Palavras-Chave}

Consumo Sustentável; Atores Sociais; Governo.

\section{THE ROLE OF GOVERNMENT AND PRACTICE OF SUSTAINABLE CONSUMPTION: HOW OPERATES THIS STAKEHOLDER IN THE ELECTRICITY SECTOR?}

\section{ABSTRACT}

The discussions involving the perspective of sustainable development are increasingly present in everyday society, from realizing the need for restructuring in practice so far adopted. In this context, it is clear that emerging issues such as sustainable consumption, which can be understood as resulting from the consumption pattern of interrelationships between social actors directed to sustainable development (MICHAELIS, 2003; JACKSON, 2007; SILVA, 2010). In fact, with the acting of different actors need to identify how each one behaves. Thus, this study aims to identify the role of government in supporting sustainable consumption, understanding that this should be involved with other actors in a given economic sector. It is used an exploratory-descriptive research with a qualitative approach, conducted in the form of a case study of the Companhia Elétrica de Pernambuco (CELPE), which seeks to contribute to the achievement of sustainable consumption in the sector. From an industry characterization of sector and of sustainable consumption, it became possible to identify the role of government in this direction, which involves many aspects that are not necessarily restricted to regulation. Thus, we see the originality and relevance of the work in the discussion on the topic of sustainable consumption.

\section{Keywords}

Sustainable consumption; Social actors; Government. 


\section{Introdução}

Continuamente, percebe-se que as transformações ocorridas em âmbito mundial, sejam elas nas áreas econômicas, sociais e/ou ambientais, indicam a necessidade de surgimento de uma nova forma de desenvolvimento que esteja direcionada para questões coletivas em detrimento dos aspectos egoístas e individualistas atualmente apregoados. Nessa perspectiva, o desenvolvimento sustentável emerge como alternativa possível de ser alcançada à medida que se discute a busca pela harmonização entre as dimensões social, econômica e ambiental, fundamentais para a efetivação desse novo modelo (SACHS, 2007).

Para que essa mudança possa ser disseminada em toda a sociedade, faz-se necessário o envolvimento de diferentes atores sociais, nomeadamente Governo, Empresa e Sociedade, que devem realizar ações de forma concomitante ao estabelecimento desse paradigma de modo que o mesmo possa ser efetivado. Tais práticas envolvem um papel mais ativo do governo, uma responsabilidade socioambiental das empresas, bem como uma maior consciência individual ao modificar suas atitudes enquanto integrante da sociedade. Essas práticas atendem aos requisitos do desenvolvimento sustentável, pela prática de um consumo sustentável (PNUMA, 2001).

Com a indissociação e interdependência entre produção, mercado e consumo, percebe-se a dificuldade em se modificar uma das partes sem que as demais também sejam modificadas (TUKKER et al., 2008). Assim, compreende-se que estão alinhadas as ações desenvolvidas pelos atores sociais tanto para com o desenvolvimento sustentável como para a efetivação de um consumo sustentável, entendendo que este último constructo se caracteriza como um padrão de consumo resultante dessas interrelações entre os atores sociais para a efetivação desse novo modelo de desenvolvimento (SILVA, 2010). Discute-se que muitos são os atores que estão envolvidos para uma reestruturação das práticas até então realizadas, a saber: Governo, Empresa, Mídia, Terceiro Setor, Sociedade Civil, dentre outros.

Na literatura sobre a prática sustentável do consumo, em sua maioria, há uma confusão entre conceitos que o equiparam com o consumo verde e o consumo consciente, o que impede o entendimento da complementaridade entre esses tipos responsáveis de consumo. Todavia, fica claro que a prática do consumo é uma questão cultural que pode ser modificada a partir de uma reestruturação nos hábitos e costumes daqueles que o praticam (SLATER, 2002; SILVA, 2010). A partir dessas considerações, ao se observar a dinâmica de mercado, à qual a sociedade está inserida, percebe-se que muitas empresas estão modificando suas práticas organizacionais e direcionando-as para questões socioambientais.

Dentre as muitas organizações que estão inseridas nesse contexto encontra-se a Companhia Elétrica de Pernambuco - CELPE, que por meio de projetos de eficiência energética vem trabalhando para uma reestruturação na prática do consumo no setor. A iniciativa de desenvolvimento desses projetos de eficiência energética está envolvida com a ideologia da empresa, mais especificamente ao que se refere a energia, foi uma regulamentação que estimulou a ampliação desses projetos criados. Dentre os muitos projetos que são desenvolvidos destaca-se o Projeto Nova Geladeira, direcionado para a disseminação de um caráter mais consciente no consumo de energia elétrica.

Com vista a essa prática desenvolvida pela organização, por entender que de alguma forma ela está envolvida numa rede de parcerias que visa o estímulo ao consumo sustentável no setor elétrico, toma-se a mesma como estudo de caso da presente pesquisa, entendendo que por meio dessas interrelações, à qual se está inserida, pode-se tomar como o objetivo de estudo identificar qual o papel desenvolvido pelo governo como auxílio ao consumo sustentável, em se considerando as especificidades do setor estudado. Com uma nova forma de atuação dos atores sociais envolvidos, percebe-se que impactos socioambientais e riscos energéticos, na forma de novos apagões, por exemplo, serão minimizados consideravelmente (WWF-BRASIL, 2007), melhorando a dinâmica setorial.

Justifica-se o estudo de um setor econômico específico, à medida que se entende que para cada setor práticas podem ser desenvolvidas no sentido de se buscar o consumo sustentável (TUKKER et al., 2008). Todavia, considerando que o ator social selecionado para o presente estudo - o Governo - atua em todos os setores da economia, torna-se possível reconhecer qual seja o papel desse ator para essa prática sustentável do consumo e difundir os resultados obtidos para outros setores econômicos, considerando-se as especificidades pertinentes a cada um desses e adaptando os apontamentos do estudo, no sentido de buscar o consumo sustentável nessas outras áreas. 
Como melhor forma de compreender o objetivo proposto, o presente artigo está dividido em cinco partes distintas. Além dessa parte introdutória, são apresentados num segundo momento os aspectos teóricos norteadores da pesquisa, assim, identifica-se uma discussão sobre desenvolvimento sustentável e consumo sustentável, com o intuito de apresentar as argumentações utilizadas para o entendimento do fenômeno. A seguir são apresentados os procedimentos metodológicos. No quarto momento, observa-se a apresentação e análise dos resultados, com uma visualização do setor elétrico, a identificação do consumo sustentável no setor, além da discussão sobre o papel do governo nesse sentido e, por fim, as considerações finais.

\section{Discussão Teórica}

\subsection{Desenvolvimento Sustentável}

As discussões envolvendo o desenvolvimento sustentável têm levado em consideração as diferentes transformações estruturais que ocorre continuamente em todo o mundo. Identifica-se que as mudanças climáticas, as crises econômicas, bem como os impactos sociais que surgem, representam os diferentes reflexos que a ação individualista do ser humano impõe ao contexto ambiental ao qual se está inserido (SILVA, 2010). Tais aspectos indicam cada vez mais a necessidade de redirecionamento da prática capitalista atual para uma que consiga abranger aspectos mais coletivos e de interesses mais amplos.

Nesse sentido, o desenvolvimento sustentável surge como alternativa a essa necessidade de mudança, considerando-se que um conjunto de ações deve ser praticado para a efetivação do mesmo. Seu conceito mais completo foi definido no Relatório de Brundtland, no qual o mesmo é entendido como "um processo de mudança em que a exploração dos recursos, a direção dos investimentos, a orientação do desenvolvimento tecnológico e a mudança institucional estão todos em harmonia" para que as necessidades humanas possam ser satisfeitas atualmente e no futuro (WCDE, 1987).

De fato, o direcionamento das atividades para uma nova forma de prática organizacional necessita de uma "mudança no pensamento mecanicista para o sistêmico, e de um sistema de valores baseado na dominação para um sistema baseado na parceria" (CASAGRANDE, 2003, p.3), indicando que o novo modelo alternativo a ser praticado serve como subsídio para as ações organizacionais, ao verificar o surgimento de uma perspectiva pautada na harmonização de três critérios fundamentais, quais sejam: equidade social, eficiência econômica e equilíbrio ambiental (SACHS, 2007), com o intuito de transformar as práticas até então desenvolvidas para essa nova visão.

A mudança de paradigma desenvolvimentista relaciona-se com a modificação na cultura social, nas práticas de consumo da população e na forma de atuação das organizações (públicas e privadas) de maneira tal que são necessárias ações de longo prazo. Desse modo, Schumacher (2001) afirma que o problema deve ser entendido em sua totalidade, buscando reconhecer e desenvolver um novo estilo de vida, com novos métodos de produção e novos padrões de consumo. Para Buarque (2008), essa transição de um modelo insustentável para outro que contemple princípios capazes de modificar positivamente o contexto deve abarcar mudanças estruturais e iniciativas transformadoras na base da organização, da sociedade e da economia.

Para que se torne possível a efetivação desse modelo de desenvolvimento emergente, percebe-se ser necessário um envolvimento entre atores sociais, de modo que seja possível a realização de atividades mais voltadas para questões socioambientais e que sejam incorporados as atitudes holísticas e a efetividade na interrelação entre os mesmos (CANEPA, 2007; SILVA, 2010). Nessa perspectiva, podem ser considerados como co-responsáveis por essa nova visão desenvolvimentista, dentre outros atores, o governo, as empresas e a sociedade civil, cada qual com seus papéis e obrigações direcionados a esse novo modelo (BUARQUE, 2008; CORRÊA, SILVA \& MELO, 2010).

Nesse contexto, percebe-se que dentre outros aspectos o governo assume o papel de regulador, fiscalizador e fomentador de ações desenvolvidas no sentido de melhor organizar a sociedade. As empresas possuem a responsabilidade de desenvolver práticas socioambientais capazes de desempenhar um melhor papel no âmbito coletivo com vistas a uma melhoria na performance dessas organizações. E a sociedade civil, além de realizar associações que visam a luta por seus direitos, possui individualmente a responsabilidade de modificar os estilos de vida populacional e padrões de consumo incompatíveis com a possibilidade de um desenvolvimento sustentável (BUARQUE, 2008, CORRÊA, SILVA \& MELO, 2010; SILVA, CORREA \& AGUIAR, 2010; SILVA, 2010). 
A partir dessas características, entende-se que a mudança na forma de atuação posta em prática é o ponto de partida inicial para que se consiga atingir um desenvolvimento endógeno, autossuficiente, orientado para as necessidades, em harmonia com a natureza e aberto às mudanças institucionais (SACHS, 2008). Esses aspectos levam a uma reflexão, sobre a necessidade de reestruturação não apenas nos modos de produção até então utilizados, como também nos padrões de consumo que nos diferentes níveis interferem, em se considerando a estruturação atual, na efetivação do desenvolvimento sustentável. Assim sendo, torna-se necessário reconhecer os aspectos basilares para o estímulo ao surgimento de um consumo sustentável, isso por meio da atuação de diferentes stakeholders.

\subsection{Stakeholders: Influências na Estrutura de Mercado}

O stakeholder pode ser considerado como elemento conceitual fundamental na análise de relacionamento e poder entre as organizações e os atores com os quais uma empresa está envolvida (HUSTED \& ALLEN, 2001; MITCHELL, ALGE \& WOOD, 1997). Esses atores influenciam e são influenciados pela organização, que são considerados muitas vezes como choques externos que pressionam diferentes formas de atuação (ABREU, 2001; PASA, 2004). Na discussão sobre a evolução da responsabilidade social, percebeu-se que os stakeholders ganharam força com a Teoria dos Stakeholders de Freeman (1984), estando os mesmos sujeitos atualmente a diferentes tipos de classificações para seu melhor entendimento. Dentre essas, Nascimento, Lemos e Mello (2008) definem que esses podem ser interno e externos à organização. Em outro momento, Clarkson (1995) indica que eles devem ser classificados como primários e secundários à influência organizacional.

Corroborando com a perspectiva desse último autor, o modelo de stakeholders de Steiner e Steiner (2006) representa de forma concisa como se dá o relacionamento entre diferentes atores sociais (empresagoverno-sociedade) à medida que considera esses atores que afetam e são afetados pela organização com diferentes níveis de influência. Os stakeholders primários interagem diretamente com a organização, em um pequeno grupo atuam de forma imediata, contínua e com certo grau de poder de acordo com cada organização. Eles são constituídos de maneira geral pelos acionistas (proprietários), consumidores, funcionários, comunidade e governo. Já os stakeholders secundários são aqueles que com menor grau de influência direta atuam sobre a organização, eles são constituídos por muitos atores que podem ser observados na Figura 1 (STEINER \& STEINER, 2006).

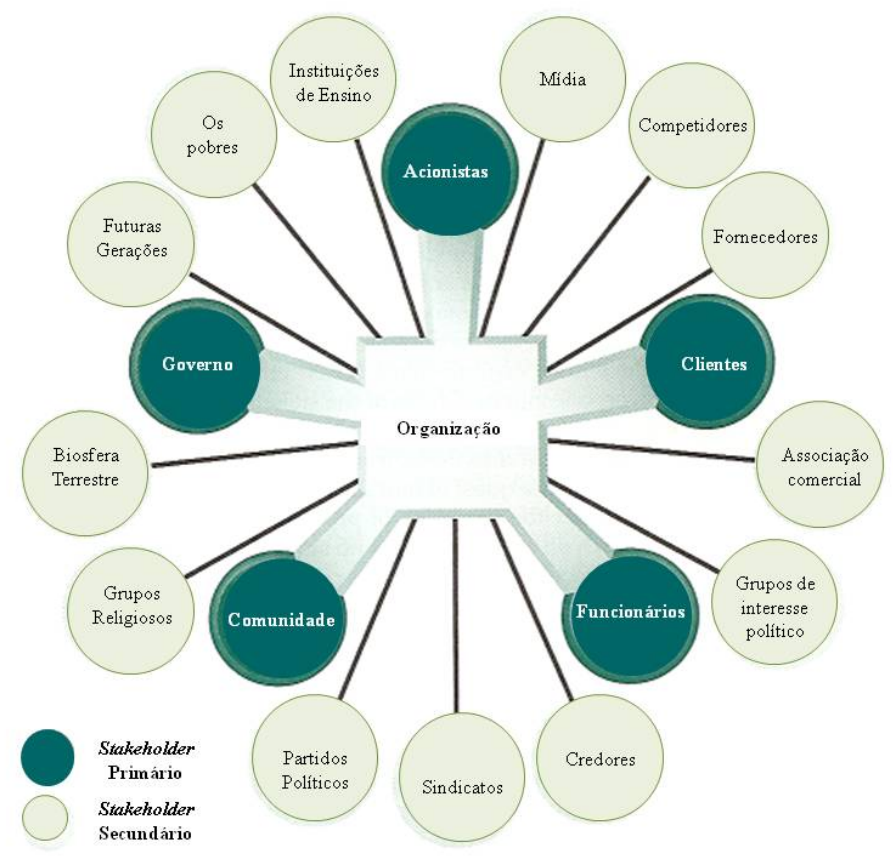

Figura 1 - Modelo de Stakeholders

Fonte: Steiner e Steiner (2006)

A partir dessa visão sobre quais os stakeholders que podem pressionar as atividades organizacionais, considerando que as organizações estão inseridas em um contexto macro com um conjunto grande de 
empresas - o mercado, fica facilitado o alcance de influências efetivas sobre a responsabilidade organizacional. A partir do momento em que se considera o governo como o ator principal de análise da presente pesquisa, dentro da ideia de interações sociais que são propostas para o consumo sustentável, percebe-se que o mesmo deve estar interagindo com todos os atores apresentados na ilustração anterior de modo tal que facilite o direcionamento de todos para uma nova perspectiva de atuação no mercado. Assim, entende-se que quando esses atores estiverem alinhados com a perspectiva do desenvolvimento sustentável de forma efetiva os mesmos conseguem também auxiliar para um consumo sustentável.

\subsection{Consumo Sustentável}

A prática do consumo acompanha o ser humano em todos os momentos de sua existência, direta ou indiretamente, o que ratifica a ideia de que é indissociável o viver sem consumir (SILVA, 2010). De acordo com o Instituto Akatu (2001), consumir é um processo que, geralmente, é realizado de forma automática e, muitas vezes, de forma impulsiva, devendo-se entender que o mesmo está relacionado com a decisão sobre o que consumir, por que consumir, como consumir e de quem consumir, além da efetivação da compra e o pós-consumo, no momento em que é necessário descartar o que foi utilizado. Esse processo pode ser observado de forma singular na compra de bens materiais e de serviços prestados.

O consumo provoca impactos em toda a sociedade, na economia e na natureza, e é por esses fatores que é necessário uma maior conscientização na hora de consumir, ou seja, é preciso que haja uma mudança nos hábitos atuais de consumo. Na visão de Bauman (2008), o consumo é condição para a sobrevivência do ser humano, ou seja, o mesmo pode ser entendido como uma característica inerente às atividades desenvolvidas individualmente em toda a sociedade. Esse consumir, na medida em que é desenvolvido de forma exacerbada, pode se tornar incontrolável, ao passo que venha a se tornar o chamado consumismo (BAUMAN, 2008; GIACOMINI FILHO, 2008). Esse excesso de consumo indica uma despreocupação dos indivíduos quanto aos aspectos da coletividade.

Considerada como uma atividade inerente a um processo cultural de uma sociedade, o consumo tem pretensões e alcance global (MCCRAKEN, 2003; SLATER, 2002), portanto, é uma atividade realizada nas diferentes nações considerando-se as particularidades de cada localidade. Desse modo, a cultura de consumo vai além da reprodução da vida cotidiana, atingindo de modo dominante um alcance prático e uma profundidade ideológica que permite estruturar e subordinar as outras culturas (SLATER, 2002). A sociedade de consumo, à qual a população está submetida na atualidade, demonstra o quão cultural a prática de consumir envolve as relações interpessoais.

Diante do consumismo observado na maioria das populações ao redor do mundo, como parte da cultura de muitos países (ASSADOURIAN, 2010), verifica-se cada vez mais necessária a mudança no modelo desenvolvimentista, alinhada a uma mudança no paradigma consumista, de modo que seja possível a continuidade nas práticas de consumo em escala mundial. Isso pode ser conquistado com a modificação do paradigma de consumo voltado a um pensamento mais holístico das ações desempenhadas (PNUMA, 2001), buscando redirecionar a visão do consumo moderno à medida que esse é caracterizado como a produção exclusiva para a venda, no mercado, aos consumidores (SLATER, 2002).

Com o evolutivo desenvolvimento do mercado direcionado a essa visão mais sistêmica quanto às características de consumo, percebe-se que o mesmo, com o passar do tempo, não é afetado somente por aqueles que são consumidores no sentido econômico, mas também por aqueles que em suas ações, mesmo que indiretamente, moldam a procura e compra de bens e serviços (PORTILHO, 2005). Evidenciase, assim, uma nova perspectiva de compra que além de valorizar as questões econômicas, buscam englobar uma maior quantidade de variáveis inerentes à oferta do produto, dentre as quais se pode identificar a preocupação empresarial com os aspectos sociais e ambientais.

A mudança nas práticas de consumo da sociedade reflete o momento cultural à qual a mesma está inserida perante as dinâmicas e demandas requeridas, necessitando-se de um direcionamento coletivo para a efetivação da forma de desenvolvimento emergente, o sustentável. Cada vez mais, seguindo a ideia de mudança de paradigma e considerando-a viável, Santos, Leite, Tacconi e Alexandre (2008) afirmam que estão surgindo novas preocupações por parte do consumidor, as quais mudam o foco individualista de seu consumo para uma visão mais ampla em termos de consciência do mesmo. Surge, portanto, o movimento na sociedade por um consumo mais responsável. 
Nesse novo contexto, com a intenção de uma nova prática de consumo diante da necessidade no desenvolvimento de novos papéis sociais direcionados a esse objetivo, que de forma ampla assume a denominação de consumo sustentável. Para que esse seja compreendido há que se identificar a existência de uma complementaridade entre tipos diferentes de consumo mais responsáveis. Percebe-se que a partir de uma ideia hierárquica entre esses tipos de consumo tornam-se geradores de complexidade numa sequência linear as ideias de consumo verde, de consumo consciente e, por fim, de consumo sustentável, alcançando, desse modo, o objetivo do novo paradigma de consumo.

Na literatura sobre a temática, percebe-se que há uma confusão entre os conceitos na visão de muitos autores nacionais, os quais buscam normalmente trabalhar com a ideia ou de consumo verde de produtos ou de práticas de consumo consciente sem a efetiva distinção entre esses (AMORIM, ARAUJO, GONÇALVES \& QUEIROZ, 2009; BARROS \& COSTA, 2008; BEDANTE \& SLONGO, 2004; BORINELLI, MORIYA, SANTOS \& COLTRO, 2009; CARDOSO \& CAIRRÃO, 2008; COSTA \& OLIVEIRA, 2009; GOMES, 2006; GONÇALVES-DIAS \& MOURA, 2007; ORTIGOZA, 2002; PANAROTTO, 2008). Todavia, Silva (2010) busca realizar um delineamento claro dessa ideia hierárquica para a compreensão da temática.

Diante dessas considerações, percebe-se que o consumo sustentável analogamente ao conceito de desenvolvimento sustentável pode ser considerado como a prática de consumo que utiliza os recursos naturais para satisfazer as necessidades atuais, sem comprometer as necessidades e aspirações das gerações futuras (GOMES, 2006; CORTEZ \& ORTIGOZA, 2007). Para que o consumo sustentável possa ser praticado, Jackson (2007) indica ser necessária uma adequação dos padrões de consumo à nova realidade social, entendendo que a partir da redução no consumo de boa parte dos materiais, bem como um redirecionamento das práticas até então desenvolvidas facilitam seu alcance.

Assim sendo, Silva (2010) define o consumo sustentável como sendo o padrão de consumo resultante da interrelação de atores sociais direcionado ao alcance do desenvolvimento sustentável, tal ideia foi desenvolvida em consonância com o modelo teórico de Michaelis (2003) (Figura 2). Assim, é necessário entender que para a prática de um consumo sustentável seja efetivo, cada um desses diferentes atores que podem ser observados possui papéis singulares às suas capacidades. Como se pode observar na ilustração a seguir, são vários os atores que se direcionam para esse consumo sustentável, e dentre os quais se pode destacar o governo, que assume particularidades a partir de sua capacidade de poder e articulação existente na sociedade. Apesar de o modelo assumir como aspecto central a empresa, o mesmo serve para mapear quais aqueles atores que atuam na rede setorial.

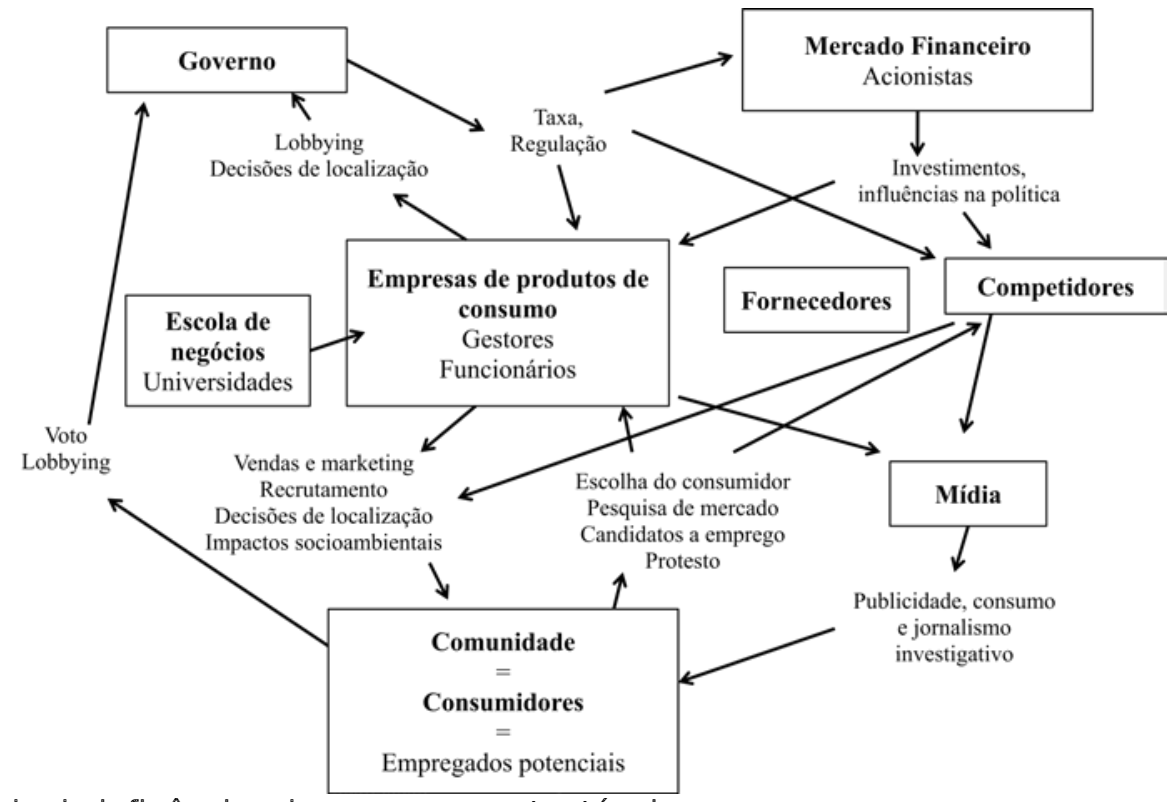

Figura 2: Mapa da rede de influências do consumo sustentável

Fonte: Traduzido de Michaelis (2003, p.916)

Assumindo como stakeholders básicos para a definição da prática social sustentável à empresa, o governo e à sociedade, percebe-se que as empresas deveriam direcionar suas atividades considerando sua responsabilidade socioambiental e melhorando sua forma de atuação no mercado (PNUMA, 2001). Uma das propostas alinhadas a esta perspectiva, está na busca por soluções inovadoras que auxiliam mais 
rapidamente o alcance do consumo sustentável em função do modelo de desenvolvimento sustentável que se almeja. Para Larantis, Gastal e Schneider (2004), a partir desse posicionamento, as empresas podem se utilizar a satisfazer a geração de consumo consciente.

O indivíduo, enquanto outro ator considerado, deve desempenhar o consumo consciente no momento de sua compra, assumindo um papel de consumidor-cidadão, entendendo que esse é o seu papel de responsabilidade para que se mude a prática de consumo apregoada. Suas ações devem estar alinhadas com a perspectiva considerada para que haja efetivamente o emergir de um novo modelo. Já o governo assume o papel de desenvolver políticas públicas e programas educacionais que auxiliem na efetivação desse novo padrão de consumo. Salienta-se uma não imersão na discussão desses papéis nesse momento, já que o presente estudo busca identificar de fato qual vem a ser o papel do governo para o consumo sustentável. A partir desse delineamento teórico, vale salientar que as diferentes economias, bem como os diferentes setores econômicos possuem práticas distintas que facilitam a efetivação do consumo sustentável (TUKKER et al., 2008).

\section{Procedimentos Metodológicos}

Com o objetivo de identificar o papel do governo no auxílio para a efetivação de um consumo sustentável, a presente pesquisa assume uma abordagem qualitativa na medida em que o fenômeno estudado especifica e representa um processo de reflexão e análise de um contexto para uma compreensão detalhada do objeto de estudo (OLIVEIRA, 2005). A utilização da referida abordagem justificase, ainda, segundo Richardson et al. (2008, p.79), "por ser uma forma adequada para entender a natureza de um fenômeno social". Para tanto, a mesma está caracterizada como pesquisa exploratória e descritiva, no sentido de melhor compreensão do estudo.

A pesquisa caracteriza-se como exploratória por proporcionar, segundo Gil (1991 p.45), uma maior familiaridade para com o problema, com vistas a torná-lo mais explícito e compreensível, e descritiva por apresentar a descrição das características de dada população ou fenômeno em estudo, com caráter conclusivo para análise (GIL, 1991; MALHOTRA, 2006). Entendendo que a temática do consumo sustentável ainda apresenta poucos trabalhos alinhados com a perspectiva de desenvolvimento sustentável continuamente discutida por diferentes atores sociais, é nesse contexto que se insere a presente pesquisa na medida em que busca-se evidenciar o papel desse importante ator social, qual seja: o governo.

Para que se torne possível o levantamento de informações pertinentes ao estudo, salienta-se que o conceito utilizado como norteador da pesquisa quanto ao consumo sustentável é aquele que indica a efetivação de um padrão de consumo, resultante de inter-relações entre atores sociais, direcionados para o desenvolvimento sustentável (SILVA, 2010). A partir dessa argumentação, identificou-se no desenvolvimento prático de suas atividades que a Companhia Elétrica de Pernambuco (CELPE) vem auxiliando para o consumo sustentável no setor elétrico, na medida em que envolvido com um grupo de atores sociais facilita o consumo consciente de seus clientes e visa à redução do impacto ambiental de suas atividades.

Desse modo, percebendo o envolvimento desses atores sociais com objetivos coletivos almejados, assume-se como método na presente pesquisa o estudo de caso, já que com as atividades dessa organização selecionada, a pesquisa se envolve num campo de reconhecimento e apresentação de características peculiares sobre a temática. O estudo de caso se apresenta como método adequado quando o investigador deseja: a) definir tópicos de forma mais superficial do que específica e aprofundada; b) cobrir condições contextuais e não apenas o fenômeno de estudo; e c) basear-se em múltiplas fontes de evidências e não em algumas poucas (YIN, 1993), facilitando desse modo, o alcance do objetivo proposto como norteador da pesquisa.

Como instrumentos de coletas de dados selecionaram-se o levantamento documental e a realização de entrevistas com representantes da organização. A utilização de documentos como fontes de dados justifica-se pela facilidade de embasamento informacional para posterior análise, essa etapa estando relacionada com a procura pelas regulamentações e/ou fomentos no setor elétrico que podem auxiliar para o entendimento do papel governamental, uma verificação na web site da empresa selecionada com o intuito de identificar informações que possam subsidiar a análise, além de notícias publicadas pela mídia que fazem menção aos projetos da empresa. Já as entrevistas foram realizadas com o representante de responsabilidade social e com o gestor de eficiência energética da empresa. Para uma melhor análise, optou-se pelo anonimato dos entrevistados. 
No que se refere à análise de dados, foi realizada uma análise de conteúdo, buscando explicitar o conteúdo das entrevistas e dos documentos, visando uma compreensão mais rápida e eficaz nos discursos diretos e simples (BARDIN, 2009). Esse tipo de análise foi realizada em três etapas: em três etapas: a) préanálise ou organização do material coletado nas entrevistas, bem como dos documentos levantados; b) análise do material propriamente dito, no qual os dados foram categorizados e embasados na literatura pertinente ao estudo; e c) tratamento dos resultados, sendo feita a interpretação destes dados e confrontando-os com os resultados obtidos na teoria, formulando-se as considerações finais. Destaca-se que foram extraídas as informações para a realização das análises, sem realizar a construção de categorias de análise nesse sentido, fato este indicado como possível na análise dos dados coletados.

\section{Apresentação e Análise dos Dados}

\subsection{Conhecendo o Setor Elétrico Brasileiro}

Com características peculiares, se comparado aos outros mercados de energia do mundo, o setor elétrico brasileiro tem sua base geradora com predominância de hidrelétricas que, apesar de ser uma fonte secundária e renovável de energia, produzem grandes impactos sobre o meio ambiente, sentidos ao longo e além do tempo de vida da usina hidrelétrica no seu entorno (SOUSA, 2000). No Brasil, a partir dos anos 1960, o segmento energético teve seu controle centralizado em poder do setor público, por meio de empresas públicas federais e estaduais, tanto no que se refere à geração, integração de sistemas e distribuição de energia (GOLDEMBERG \& PRADO, 2003).

Como reflexo da crise fiscal que ocorreu no país no final dos anos 1980 e com os adiamentos das necessidades de expansão da oferta de energia, tornou-se impossibilitado para as empresas estatais a manutenção nos investimentos necessários para o setor elétrico, o que propiciou a entrada da iniciativa privada e a privatização dos ativos existentes nesse mercado de forma pulverizada. Todavia, como afirma Leme (2009), não houve inicialmente, nesse processo de privatização, a criação por parte do Estado de mecanismos necessários para a nova regulação do setor, o que gradativamente foi sendo trabalhado e organizado pelo governo como forma de melhorar as práticas no setor.

Nesse contexto de transição, ocorreu uma série de reformas no setor, com uma série de políticas regulatórias até que chegou ao novo modelo institucional do sistema energético nacional, inaugurado pela lei 9.427/96, que instituiu a ANEEL (Agência Nacional de Energia Elétrica), e a lei 9.648/98, que definiu as regras de entrada, tarifas e estrutura de mercado, entre outras coisas (PIRES, 2000). Com o surgimento de um ambiente concorrencial no setor elétrico, segundo Fernandino e Oliveira (2010), as empresas viram-se inseridas numa perspectiva ambiental e organizacional, na qual se mostrava necessário definir estratégias para sua atuação, bem como o ajustamento de suas estruturas e delineamento de processos internos para uma melhor adaptação a esse novo contexto.

Na década de 2000, ao atravessar um período de escassez de chuvas, ao considerar-se a grande quantidade de hidrelétricas no país, surgiu a necessidade de novas formas de geração da matriz energética nacional. Nesse contexto, destacam-se nessa nova geração energética as termelétricas (biomassa) e o gás natural, tendo o governo que adotar medidas de apoio ao desenvolvimento de projetos de hidrelétricas, de fontes não-convencionais e de conservação de energia (GRUPO NEOENERGIA, 2008). Concomitantemente à evolução e dinâmica reconhecida no setor elétrico brasileiro, ao longo dos anos surgiram as empresas responsáveis pela geração e distribuição de energia.

Dentre aquelas que foram criadas nesse período temporal de evolução do setor elétrico brasileiro encontra-se a Companhia Energética de Pernambuco - CELPE. Fundada em 10 de fevereiro de 1965 com o papel de distribuidora de energia do Estado de Pernambuco, a empresa passa a ter caráter privado no final da década de 1990, quando foi adquirida em leilão por um consórcio chamado de Guaraniana, formado pela Caixa de Previdência dos Funcionários do Banco do Brasil (PREVI), pela carteira de investimentos do Banco do Brasil (BB S/A) e pelo Grupo Iberdrola, reconhecida hoje como Grupo Neoenergia (CELPE, $2010 a$ ). Atualmente a CELPE atende a mais de três milhões de clientes e leva energia a 184 municípios pernambucanos, ao distrito de Fenando de Noronha e ao município de Pedras de Fogo, no Estado da Paraíba (CELPE, 2010b).

Na prestação de seus serviços, a empresa adotou uma gestão socialmente responsável, implementando suas ações de responsabilidade social e sustentabilidade por meio de programas estruturados, assumindo destaque nacional entre as melhores distribuidoras de energia do Brasil (CELPE, 2010b). A atuação social 
da empresa estudada focaliza questões de cultura, educação e meio ambiente, sendo desenvolvidos projetos com o objetivo de atender a esse foco, tendo como exemplo de atuação os projetos: Luz no Empreendedorismo, Ação Integrada, Telecentro Comunitário, Agente Celpe, Logisverde, Encontro Celpe e Comunidades Especiais.

Um dos principais meios de desenvolver as ações de responsabilidade social da empresa é por meio de projetos de Eficiência Energética, que contemplam alguns desses focos e têm o objetivo de proporcionar à sociedade um uso mais eficaz e racional da energia elétrica, evitando os desperdícios e reduzindo também os custos incorridos com seu uso. Dentre esses projetos destaca-se o chamado Projeto Nova Geladeira que está envolvido numa rede de parcerias, com a qual estimula-se o consumo consciente de energia da população de baixa renda beneficiada pelo projeto, e com isso em meio as interações sociais que desenvolve para a execução do projeto, estimula a efetivação do consumo sustentável no setor elétrico.

\subsection{Consumo Sustentável no Setor Elétrico: Uma Visão Macro.}

Para questões de análise desse estudo, considerando-se a quantidade de práticas desenvolvidas pela empresa, selecionou-se a análise do Projeto Nova Geladeira como aspecto ilustrativo da facilitação à prática do consumo sustentável, entendendo e considerando que o mesmo é desenvolvido pelas distribuidoras de energia do Grupo Neoenergia, considerando exclusivamente os aspectos operacionais apresentados pela CELPE, empresa estudo de caso do presente trabalho. A partir do ano 2000, com a aprovação da lei 9.991/00 (atuação do Governo), que dita que as empresas concessionárias ou permissionárias de energia elétrica no Brasil deveriam aplicar uma percentagem de sua receita operacional líquida (ROL) em programas de eficiência energética, a empresa começou a realizar ações de responsabilidade social por meio dos seus projetos, tal fato ocorreu mais especificamente no ano 2001.

Dentre os muitos projetos desenvolvidos pela Empresa, aquele considerado como um dos principais do Grupo Neoenergia, o Projeto Nova Geladeira, consiste na troca de geladeiras velhas de alto consumo de energia por uma nova geladeira com selo PROCEL de economia de energia. Num primeiro momento, o projeto pode não apresentar muitas contribuições para o contexto social, mas em se observando as contribuições e possibilidades resultantes do mesmo, admite-se que a ideologia da empresa, de reestruturação na maneira de consumo da população beneficiada é plausível. O projeto iniciou suas atividades em 2006, quando em parceria com o Banco do Brasil (Instituição financiadora), por meio do Banco Popular, a empresa proporcionou a população beneficiada a compra de geladeiras a um preço abaixo do mercado.

A partir de 2008, a empresa passa a trocar as geladeiras velhas por novas e mais eficientes em toda a Região Metropolitana do Recife e alguns municípios do interior do estado com os Agentes Celpe (Funcionários), com o objetivo de propagar os conceitos de uso eficiente e seguro de energia elétrica. A ideia previa, além do estímulo à redução no consumo elétrico por parte da comunidade, um processo de conscientização capaz de alertar a população da necessidade de economia com os diferentes eletrodomésticos de sua residência. Segundo o representante de eficiência energética da empresa, esse processo se dava "através de palestras ou orientação personalizada para explicar os conceitos de uso eficiente e seguro de energia e preservação do meio ambiente". Esse projeto, na visão da representante de RSE da empresa, está em consonância com a prática da responsabilidade social da empresa, "na medida em que noções básicas de educação e consumo consciente são repassadas para uma população carente de informações sobre as formas de preservação do ecossistema".

Com a ampliação dos beneficiados a cada ano do projeto, a empresa começou a trabalhar com instituições do terceiro setor, como parceiras para a execução do projeto, aquela que atua diretamente nesse projeto é a Associação de Voluntários para o Serviço Internacional - AVSI, uma Organização NãoGovernamental (ONG) atuante na capital pernambucana. As principais metas a serem atingidas até dezembro de 2011 é a realização de 90.000 visitas a residências, troca de 50.000 geladeiras e de 180.000 lâmpadas fluorescentes, além da continuidade do processo de conscientização sobre eficiência energética por parte da empresa. Vale salientar, que a troca das lâmpadas é uma atividade inclusa no projeto macro da troca de geladeiras, alinhada à questão da eficiência energética.

Na Mídia do estado, por meio de noticiários impressos ou virtuais, constantemente são identificadas notícias que enaltecem o caráter responsável que a empresa desenvolve com esse projeto, mostrando benefícios e parcerias que são desenvolvidas em torno do objetivo principal do projeto. Dentre as reportagens, identificam-se parcerias entre a CELPE e prefeituras da Região Metropolitana do Recife e do 
interior do estado, além das desenvolvidadas com outras organizações do terceiro setor, como o Instituto Walmart, com o intuito de beneficiar comunidades atendidas por seus projetos (CELPE, 2010C; DIÁRIO DE PERNAMBUCO, 2010; FOLHA PE; 2010). Desse modo, percebe-se que estão havendo interações entre os diferentes atores sociais no sentido de dar continuidade à prática de consumo, mas de forma reestruturada e direcionada para um desenvolvimento sustentável.

Compreendendo que o consumo sustentável relaciona-se com o estímulo à efetivação de um novo padrão de consumo, a partir das interrelações dos atores sociais e direcionado para a forma de desenvolvimento emergente (SILVA, 2010), é possível afirmar que está havendo o estímulo a partir das práticas apresentadas nesse trabalho, na medida em que todos os atores sociais anteriormente listados estão envolvidos com um objetivo comum que é a busca por uma nova prática de consumo, mais eficiente e responsável pelo consumidor final. Percebe-se que existe uma rede de interrelações entre esses atores sociais, que, de forma complementar, conseguem estimular e mudar a prática de consumo final da energia.

A partir do momento em que o governo atuou como agente regulador, assumindo a responsabilidade pela estruturação de um setor econômico, no caso o energético, a empresa viu-se envolvida com a necessidade de mudança nas suas atividades cotidianas. Nesse momento, a empresa estimulada pela regulamentação assumiu a responsabilidade, que nesse caso seria a de desenvolver projetos condizentes com os critérios estabelecidos na lei, mas que representassem as suas ideologias, ou seja, que alinhassem o que foi imposto com o objetivo da organização. Ao incorporar essa responsabilidade, as atividades desenvolvidas pela organização, envolvidas com a Educação, Cultura e Meio Ambiente, puderam ser abordadas nos vários projetos nesse sentido.

A partir do momento em que iniciou o processo de efetivação do Projeto Nova Geladeira, estudado até então, a empresa buscou parceria com o Banco do Brasil, ou seja, outro ator social uma Instituição Financiadora, capaz de auxiliar com as ideias da organização, isso com o foco no consumidor, nesse caso o ator social mais beneficiado com as parcerias e interações até então desenvolvidas. O consumidor, além de estar envolvido com o processo de conscientização e de ganho com a nova geladeira, deve assumir a sua responsabilidade de economizar energia para que toda a sociedade venha a ganhar, desse modo a empresa também estimula essa conscientização por parte do indivíduo beneficiado.

Nesse caminho de contribuição para um consumo sustentável no setor elétrico, observa-se claramente a atuação de pelo menos mais dois atores sociais, que são o funcionário da empresa, chamado de Agente Celpe, responsável pelo contato com o beneficiário e em muitos casos pelo ponto inicial na conscientização desse indivíduo, ou seja, apesar de representar a empresa, o colaborador enquanto indivíduo tem sua responsabilidade nesse contexto maior trabalhado. Outro ator a ONG, por meio da operacionalização do projeto está se envolvendo com a comunidade e pode estar envolvida ainda com o processo de conscientização e com esse novo perfil de consumo estimulado.

De forma mais parcial, a mídia entra como ator social com o poder de demonstrar como as ações da CELPE estão sendo desenvolvidas, e como se observou nas reportagens analisadas, na maioria das vezes reconhece-se a contribuição positiva que o projeto tem no desenvolvimento de suas atividades. Esses atores podem ser mapeados no modelo de rede de influências de Michaelis (2003) para facilitar a contribuição existente dessas relações para o consumo sustentável (Figura 3).

De fato, ao se considerar a sistematização complexa à qual a execução desse projeto assume, na medida em que envolve uma grande gama de atores sociais, a saber: Governo, Empresa, Instituição Financiadora, Comunidade (Indivíduos), Funcionário, Mídia, Organização do Terceiro Setor, recebendo resultados positivos o Meio Ambiente e possivelmente outros atores que não foram identificados a partir dos dados levantados nessa pesquisa, pode-se dizer que está havendo efetivamente um estímulo por parte dessas relações para o alcance de um consumo sustentável, na área de consumo de energia, seguindo essa ideia até então apresentada. Isso se apresentou como possível a partir do momento em que o ator social Governo, na medida em que a partir das regulamentações e contínuas atualizações desenvolvidas na sua interação com todo o mercado, obteve um papel de fundamental importância nesse processo direcionado ao consumo sustentável. 


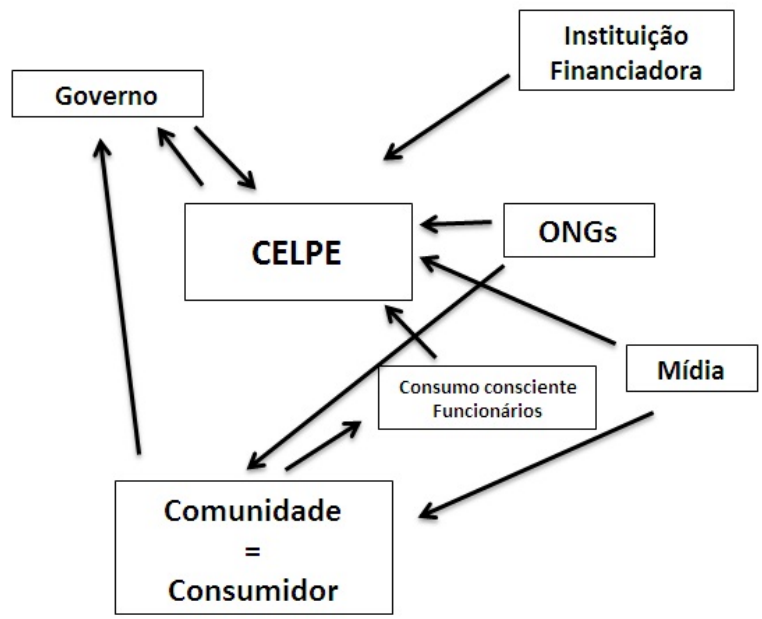

Figura 3: Mapa de stakeholders da CELPE

Fonte: Baseado em Michaelis (2003)

Como se vem discutindo até então, cada stakeholder tem que assumir seu papel e desenvolver suas responsabilidades e obrigações para com todos os demais atores de determinados setores econômicos, no presente caso, percebe-se que o Governo conseguiu iniciar todo o ciclo de ações ou sistema que envolve um setor econômico, no caso o energético, direcionado ao alcance de um consumo sustentável, mesmo que indiretamente. Salienta-se que a apresentação desses dados suporta o alcance do objetivo proposto que é a identificação do papel do governo, ao se obter uma visão macro das atividades desenvolvidas. Desse modo, torna-se possível reconhecer como o governo pode auxiliar para esse padrão sustentável de consumo.

\subsection{O Papel do Governo para o Consumo Sustentável: Entendendo a Atuação desse Ator Social}

A compreensão do papel do governo para o consumo sustentável, em função dessa prática sustentável de consumo no setor elétrico apresentada anteriormente, facilita o entendimento da atuação desse ator na perspectiva estudada. Salientando que este trabalho não busca esgotar a discussão sobre a temática, nem mesmo engessar as formas de atuação desse ator, sua contribuição está no despertar acadêmico sobre a necessidade de consideração de diferentes atores sociais nessa área de estudo. Assim sendo, para o atendimento do objetivo proposto fez-se uma contextualização sobre a prática sustentável de consumo, discute-se como o governo atuou nesse sentido, e apresentam-se alguns aspectos que facilitam o disseminar dos resultados para outros setores econômicos.

Para que o consumo sustentável seja efetivado no setor elétrico, a atuação do governo assumiu aspecto de fundamental importância. A partir do momento em que ele redefiniu sua forma de atuação que classicamente consistia em regulamentar a operação do monopólio no setor; definir e encaminhar políticas de interesse geral; e funcionar como proprietária enquanto empresas públicas (GOLDEMBERG \& PRADO, 2003) para a criação de um mercado livre, ainda segundo os autores, por meio de incentivos à eficiência, identificou-se a intervenção de forma positiva do governo nesse contexto de produção-consumo energético.

Desse modo, de acordo com a lei 9.991 (2000), As concessionárias e permissionárias de serviços públicos de distribuição de energia elétrica ficam obrigadas a aplicar [...] no mínimo, vinte e cinco centésimos por cento em programas de eficiência energética no uso final. [...] As receitas de que trata este artigo deverão ser aplicadas nas seguintes atividades do setor elétrico:

I - em programas de universalização do serviço público de energia elétrica;

II - no financiamento de projetos socioambientais;

III - em projetos de eficiência e pesquisa energética; e

IV - no pagamento de faturas de energia elétrica de unidades consumidoras de órgãos estaduais e municipais. 
Como se observa, o governo desenvolveu seu papel de forma direta na busca por melhor estruturação do setor. Para Fernandino e Oliveira (2010), o objetivo principal do governo quando criou essa lei era assegurar o desenvolvimento tecnológico e de gestão do setor elétrico. Esse fato para o WWF-Brasil (2007) está relacionado com a criação de cenários para setor, dentre os quais se pode observar o Cenário Elétrico Sustentável, no qual o governo precisa aprovar e programar um plano estratégico para um setor mais eficiente e inovador, com medidas de eficiência energética e maior utilização de fontes renováveis de energia, como biomassa, eólica, solar e pequenas hidrelétricas.

Segundo a organização, se o cenário Elétrico Sustentável for aplicado no Brasil em 2020 haverá uma redução de até $40 \%$ na demanda de energia elétrica. Diante de todas essas considerações, torna-se visível que o governo deve continuar atuante de forma ativa no sentido de melhorar as práticas desenvolvidas. Nesse sentido, nos diferentes setores econômicos direta ou indiretamente deve haver um envolvimento por parte do ator governamental no sentido de contribuir positivamente para um consumo sustentável. Entendendo que muitas vezes o governo surge como o estimulador inicial para que sejam reestruturadas práticas desenvolvidas setorialmente.

Com o objetivo maior de efetivar o alcance de um consumo sustentável, cada um desses atores sociais deve assumir papéis e obrigações distintas nesse sentido. Ao selecionar o governo como foco desse trabalho, na literatura que discorre pela temática percebe-se que esse ator pode promover e facilitar o desenvolvimento de tecnologias limpas, bem como transferi-las e adotá-las em todas as áreas da economia. O mesmo ainda tem o papel de apoiar pesquisas para o fornecimento de informações de produção e consumo, tanto para a indústria como para os consumidores, considerando a intenção direcionada para o desenvolvimento sustentável (PNUMA, 2001). Essas ações na visão de Taylor (2006) podem ser desenvolvidas em qualquer um dos níveis de atuação governamental, sejam eles nacionais, estaduais ou regionais (municipais), por meio de regulamentações ou incentivos.

De acordo com Andrade (1998, p.65) "os governos podem adotar medidas de comando-e-controle (legislação e estabelecimento de padrões de consumo e produção), adotar também instrumentos sociais (educação e campanhas de informação), instrumentos econômicos (políticas físicas e de preço)". Todos esses aspectos, facilitando um papel ativo de atuação, no qual ele pode regulamentar, fiscalizar, fomentar/investir alinhado com essa nova perspectiva. De fato, nota-se ser imprescindível que o governo assuma o seu papel entendendo que por meio, por exemplo, de políticas públicas e programas educacionais conseguirá desenvolver ou incentivar outros atores para a tais práticas sustentáveis.

Na visão de Jackson e Michaelis (2003), a politica governamental tem condições de influência no comportamento social, cultural, institucional e ético nas escolhas do consumidor individual, isso se dando por meio de suporte e encorajamento de iniciativas por escolas, ONGs, grupos da comunidade e organizações religiosas, havendo desse modo uma contribuição positiva do papel do governo em uma inovação social dentro dessa perspectiva sustentável de consumo. Como se percebe, são muitas as formas de atuação que o governo pode assumir e direcionar suas ações no decorrer de suas atividades governamentais, facilitando assim a busca pela efetivação do consumo sustentável. Apesar de todas essas considerações, apresenta-se como plenamente possível o desenvolvimento de outros trabalhos mais direcionados a questão das políticas públicas e da cidadania individual e corporativa.

\section{Considerações Finais}

Para a efetivação do desenvolvimento sustentável, percebe-se ser necessária uma reestruturação nas práticas desenvolvidas pelos diferentes atores sociais atuantes nesse processo, essas estando alinhadas em um primeiro momento com o alcance de um consumo sustentável para posterior implementação do novo modelo desenvolvimentista. Vale salientar que, como discutido até o presente momento, são muitas as ações que podem ser desenvolvidas por cada ator social para o alcance do objetivo maior. De fato, justifica-se a necessidade de envolvimento na medida em que individualmente nenhum ator consegue a mudança macro almejada, apesar de conseguir a modificação na sua área de atuação, por exemplo, uma empresa pode praticar a responsabilidade socioambiental e não ser reconhecida e auxiliada.

Como se pode observar na Figura 03, existe um conjunto de interações entre os stakeholders, seguindo a perspectiva de Michaelis (2003), que indica um processo de ação e reação por parte da CELPE, já que suas práticas de Responsabilidade Socioambiental foram intensificadas a partir de uma pressão governamental e que a mesma conseguiu interagir com um grupo de atores para que as práticas até então 
desenvolvidas no setor pudessem ser reestruturadas e direcionadas para uma visão mais responsável em todos os atores. Quando a empresa começou a desenvolver suas ações, ao incorporar às estratégias práticas mais responsáveis, a mesma conseguiu criar movimentações em outros atores, como no caso da mídia, por exemplo, que começou a reconhecer esse diferencial na organização. Além disso, a mesma buscou estimular um consumo consciente de energia com a realização de programas de conscientização, por isso, entende-se que foram essas interações que indicaram esse direcionamento organizacional à uma prática sustentável de consumo.

Nesse contexto de interações, percebe-se que ações desenvolvidas pela CELPE contribuem para o alcance do consumo sustentável no setor elétrico na medida em que consegue envolver uma grande quantidade de atores sociais direcionados ao desenvolvimento sustentável. Assim, percebe-se que Governo, Empresa, Comunidade, Mídia, Terceiro Setor, Funcionários, Instituições Financiadoras, dentre outros atores sociais, tem papéis específicos e imprescindíveis nessa nova prática coletiva. Para questões desse estudo, na medida em que se selecionou o estudo de caso, destaca-se o papel responsável da CELPE na busca pela eficiência energética no consumo da energia, o que contribui muito positivamente.

Todavia, como o objetivo do estudo focava a identificação do papel governamental direcionado para auxiliar o consumo sustentável, ao se analisar o setor elétrico, resultados importantes foram identificados. Com a análise da evolução do setor, com a apresentação do direcionamento setorial para o consumo sustentável, a partir do Projeto Nova Geladeira desenvolvido pela empresa selecionada, identificou-se que - Governo tem o papel de promover e facilitar o desenvolvimento de tecnologias limpas, de apoiar pesquisas para o fornecimento de informações sobre a produção e consumo, de criar medidas de comandoe-controle e instrumentos sociais e econômicos, além de regular, fiscalizar, fomentar, investir, incentivar os diferentes setores econômicos ao desenvolvimento de novas práticas.

Nesse contexto, para cada setor da economia, bem como para as diferentes classes econômicas identificadas na sociedade, é de suma importância que o governo esteja envolvido e ativamente integrado nesse processo de estímulo a promoção de um consumo sustentável e, por conseguinte, do desenvolvimento sustentável, considerando que esse resultante de uma integração global dos diferentes tipos de reestruturações, na produção e no consumo, pela complexidade que apresenta. Assim sendo, identificam-se a relevância e a originalidade da presente pesquisa já que se consegue atender ao objetivo proposto e contribuir para a discussão sobre a temática. Toma-se como limitação da pesquisa a análise de apenas um projeto na empresa selecionada, mas entende-se que aquele analisado apresenta contribuições positivas para as discussões. Para novos trabalhos, recomenda-se a ampliação da análise dos projetos, caso seja considerada a empresa o foco do estudo, ou ainda, a realização da pesquisa sobre consumo sustentável em diferentes setores da economia.

\section{Referências}

Abreu, M. C. S. (2001) Modelo de avaliação da estratégia ambiental: Uma ferramenta para tomada de decisão. 232p. Tese (Doutorado em Engenharia de Produção). Programa de Pós-graduação em Engenharia de Produção. Universidade Federal de Santa Catarina. Florianópolis.

Amorim, B. C.; Araujo, A. C. C.; Gonçalves, G. A. C. \& Queiroz, C. T. A. P. (2009). Diagnóstico da consciência ambiental dos gestores: Eco-atitudes e consumo sustentável em Campina Grande/PB - Brasil. (v.8, n.2) Qualit@s Revista Eletrônica.

Andrade, N. L. S. (1998) Consumo sustentável. (n.59, p. 181-184) Revista Justitia, São Paulo.

Assadourian, E. (2010) Ascensão e queda das culturas de consumo. In: WORLDWATCH INSTITUTE. Estado do Mundo, 2010: estado do consumo e o consumo sustentável. Salvador: Uma Ed.

Bardin, L. (2009). Análise de Conteúdo. (4a ed.) Lisboa: Edições 70.

Barros, D. F. \& Costa, A. M. (2008) Consumo consciente no Brasil: Um olhar introdutório sobre práticas de resistência ao consumo por meio de análises de discurso do Instituto Akatu pelo consumo consciente. Anais do XXXI/ Encontro da ANPAD - EnANPAD. Rio de Janeiro: FGV-EBAPE.

Bauman, Z. (2008) Vida para o consumo: a transformação de pessoas em mercadorias. Rio de Janeiro: Jorge Zahar Ed.

Bedante, G. N. \& Slongo, L. A. (2004) O comportamento do consumo sustentável e suas relações com a consciência ambiental e a intenção de compra de produtos ecologicamente embalados. Anais do / Encontro de Marketing da ANPAD - EMA. Porto Alegre: EA-UFRGS. 
Borinelli, B.; Moriya, I.; Santos, L. M. L. \& Coltro, F. L. (2008) Regulação Ambiental e Consumo Sustentável: uma discussão a partir da percepção dos consumidores de Londrina-PR. Anais do /// Encontro de Administração Pública e Governança da ANPAD. Salvador: UFBA.

Buarque, S. C. (2008) Construindo o desenvolvimento local sustentável: metodologia de planejamento. São Paulo: Garamond.

Canepa, C. (2007) Cidades sustentáveis: o município como locus da sustentabilidade. São Paulo: RCS Editora.

Cardoso, A. J. M. \& Cairrão, A. M. C. L. (2007) Os jovens universitários e o consumo sustentável: A sua influência na compra de produtos ecológicos. (n. 4, p. 124-135) Revista da Faculdade de Ciência e Tecnologia.

Casagrande, E. F. (2003) Inovação Tecnológica e Sustentabilidade: integrando as partes para proteger o todo. [ Palestra do Seminário de Tecnologia - PPGTE] Curitiba: CEFET-PR.

CELPE (Companhia Elétrica de Pernambuco). (2010a) A História. [ Online]. Disponível em: <http://www.celpe.com.br/> Acesso em: dez. 2010.

CELPE (Companhia Elétrica de Pernambuco). (2010b) A CELPE: Pernambuco tem a energia da Celpe. [Online]. Disponível em: <http://www.celpe.com.br/> Acesso em: dez. 2010.

CELPE (Companhia Elétrica de Pernambuco). (2010c) Celpe firma convênio com o Instituo Walmart e o Estaleiro Atlântico Sul. [ Online]. Disponível em:

<http://www.celpe.com.br/SALA\%20DE\%20IMPRENSA/RELEASES/release.asp?c $=137 \&$ cod $=222>$ Acesso em: dez. 2010.

Clarkson, M. B. E. (1995) A stakeholder framework for analyzing and evaluating corporate social performance. (v. 20, n. 1, p. 92-117) Academy of Managment Review.

Corrêa, A. P. M.; Silva, M. E. \& Melo, E. S. (2010) A logística reversa como componente facilitador da interrelação entre empresas, governo, e sociedade em busca do desenvolvimento sustentável. Anais do XII Encontro Internacional de Gestão Empresarial e Meio Ambiente. São Paulo: FGV-EAESP.

Cortez, A. T. C. \& Ortigoza, S. A. G. (2007) Consumo Sustentável: conflitos entre necessidades e desperdício. São Paulo: Editora UNESP.

Costa, F. J. \& Oliveira, L. G. L. (2009) Produção e consumo sustentável: Um estudo de caso. Anais do X/I Simpósio de Administração da Produção, Logística e Operaçóes Internacionais - SIMPOI. São Paulo: FGVEAESP.

Diário de Pernambuco. (2010) Prefeitura e Celpe vão trocar geladeiras de beneficiados pelo Pró-metropole. [Online]. Disponível em:

<http://www.diariodepernambuco.com.br/economia/nota.asp?materia $=20100527074654 \& a s s u n t o=69 \&$ on de=Economia > Acesso em: dez. 2010.

Fernandino, J. A. \& Oliveira, J. L. (2010) Arquiteturas organizacionais para a área de P\&D em empresas do setor elétrico brasileiro. (vol.14, n.6, pp. 1073-1093) Revista Administração Contemporânea [ online].

Folha PE. (2010) Mais 800 unidades de geladeiras serão distribuídas na RMR e Sertão. [ Online]. Disponível em: <http://www.folhape.com.br/index.php/noticias-geral/33-destaque-noticias/608174-800-unidades-narmr-e-sertao> Acesso em: dez. 2010.

Freeman, R. E. (1984) Strategic Management: a Stakeholder Approach. Boston, MA: Pitman.

Giacomini Filho, G. (2008) Meio Ambiente \& Consumismo. São Paulo: Editora Senac São Paulo.

Gil, A. C. (1991) Como Elaborar Projetos de Pesquisa. 3. ed. São Paulo: Atlas.

Goldenberg, J. \& Prado, L. T. S. (2003) Reforma e crise do setor elétrico no período FHC. (vol.15, n.2, pp. 219-235) Tempo social[ online].

Gomes, D. V. (2006) Educação para o Consumo Ético e Sustentável. (v.16) Revista eletrônica Mestrado em Educação Ambiental.

Gonçalves-Dias, S. L. F. \& Moura, C. (2007) Consumo Sustentável: muito além do consumo "verde". In Anais... XXXI Encontro da ANPAD - EnANPAD. Rio de Janeiro: FGV-EBAPE.

Grupo Neoenergia. (2008) Histórico do setor elétrico. Disponível em:

<http://www.neoenergia.com/section/historico-setor-eletrico.asp> Acesso em: dez. 2010.

Husted, B. W. \& Allen, D. B. (2001) Toward a model of corporate social strategy formulation. Proceedings of the Social Issues in Management Division at Academy of Management Conference, Washington D.C., Washington, Estados Unidos. 
Instituto Akatu. (2001) Akatu pelo consumo consciente. Disponível em: <http://www.akatu.org.br/>. Acesso em: nov. 2010.

Jackson, T. \& Michaelis, L. (2003, September) Policies for sustainable consumption. A Report to the sustainable development commission.

Jackson, T. (2007) Sustainable Consumption. In: ATKINSON, G.; DIETZ, S.; NEUMAYER, E. (editors). Handbook of Sustainable Development. Edward Elgar Publishing.

Larentis, F.; Gastal, F. \& Schneider, H. (2004) Influência de diferentes formas de persuasão na intenção de consumo consciente: um desing experimental. Anais do / Encontro de Marketing da ANPAD. Porto Alegre: EA-UFRGS.

Lei no 9.991. (2000) Planalto Central. Disponível em:

<http://www.planalto.gov.br/ccivil_03/Leis/L9991.htm> Acesso em: dez. 2010.

Leme, A. A. (2009) A reforma do setor elétrico no Brasil, Argentina e México: contrastes e perspectivas em debate. (vol.17, n.33, pp. 97-121) Revista de Sociologia e Política [online].

Malhotra, N. (2006) Pesquisa de Marketing: uma orientação aplicada. (4a ed.) Porto Alegre: Bookman.

Mccracken, G. (2003) Cultura e consumo: novas abordagens ao caráter simbólico dos bens e das atividades de consumo. Rio de Janeiro: MAUAD.

Michaelis, L. (2003) The role of business in sustainable consumption. (v.11, p. 915-921) Journal of Cleaner Production.

Mitchell, R. K.; Agle, B. R. \& Wood, D. J. (1997) Toward a Theory of Stakeholder Identification and Salience: Defining the Principle of Who and What Really Counts. The Academy of management review.

Nascimento, L. F.; Lemos, Â. D. C. \& Mello, M. C. A. (2008) Gestão socioambiental estratégica. Porto Alegre: Bookman.

Oliveira, M. M. (2005) Como fazer pesquisa qualitativa. Recife: Ed. Bagaço.

Ortigoza, S. A. G. (2002) Consumo sustentável: um compromisso de todos. (v. 2, n. 2) Território \& Cidadania.

Panarotto, C. (2008) O meio ambiente e o consumo sustentável: alguns hábitos que podem fazer a diferença. Revista das relações de consumo. Caxias do Sul.

Pasa, C. R. R. (2004) Modelo de Avaliação da Performance Social Empresarial. 277p. Tese (Doutorado em Engenharia de Produção). Programa de Pós-graduação em Engenharia de Produção. Universidade Federal de Santa Catarina. Florianópolis.

Pires, J. C. L. (2000) Desafios da reestruturação do setor elétrico. Textos para discussão 76. BNDES. Disponível em:

<http://www.bndes.gov.br/SiteBNDES/export/sites/default/bndes_pt/Galerias/Arquivos/conhecimento/td/Td76.pdf> Acesso em: dez. 2010.

Pnuma (Programa das Nações Unidas para o Meio Ambiente). (2001) Rumo ao consumo sustentável na América latina e caribe. [ Workshop sobre consumo sustentável na América latina e caribe] São Paulo.

Portilho, M. F. F. (2005) Sustentabilidade Ambiental, consumo e cidadania. São Paulo: Cortez.

Richardson, R. J.; Peres, J. A. S.; Wanderley, J. C. V; Correia, L. M. \& Peres, M. H. M. (2008) Pesquisa Social: métodos e técnicas. (3a ed.) São Paulo: Atlas.

Sachs, I. (2007) Rumo à ecossocioeconomia: Teoria e prática do desenvolvimento. São Paulo: Cortez.

Sachs, I. (2008) Caminhos para o desenvolvimento sustentável. Rio de Janeiro: Garamond.

Santos, T. C.; Leite, A. P. R.; Tacconi, M. F. F. S. \& Alexandre, M. L. (2008) Movimento do Consumo Consciente: do Cidadão Consumidor ao Consumidor Cidadão? Anais do Encontro de Administração Pública e Governança - EnAPG. Salvador: UFBA.

Schumacher, E. F. (2001) Lo pequeno es hermoso. (3a Ed.) Espana: Tursen S.A.

Silva, M. E. (2010) Consumo Sustentável: Em busca de um constructo. Anais do X/I Encontro Internacional de Gestão Empresarial e Meio Ambiente. São Paulo: FGV-EAESP.

Silva, M. E.; Corrêa, A. P. M. \& Aguiar, E. C. (2010) Consumo e Sustentabilidade: A perspectiva educacional para o consumo consciente. Anais do // Encontro Regional de Tecnologia e Negócios - ERTEN. Serra Talhada: UFRPE.

Slater, D. (2002) Cultura do consumo \& modernidade. São Paulo: Nobel. 
Sousa, W. L. (2000) Impacto ambienta/ de hidrelétricas: Uma análise de duas abordagens. $154 \mathrm{f}$. Dissertação (Mestrado em Ciências em Planejamento Energético). Programa de Pós-graduação em Engenharia. Universidade Federal do Rio de Janeiro. Rio de Janeiro.

Steiner, G. A. \& Steiner, J. F. (2006) Business, government and society: A managerial perspective, text and cases. (11th ed.) Nova York: McGraw-Hill/Irwin.

Taylor, B. (2006) Encouraging industry to assess and implement clear production measures. (v. 14) Journal of cleaner production.

Tukker, A.; Emmert, S.; Charter, M.; Vezzoli, C.; Sto, E.; Andersen, M. M.; Geerken, T.; Tischner, U. \& Lahlou, S. (2008) Fostering change of sustainable consumptiom and production: an evidence based view. (v. 16) journal of cleaner production.

WCED - World Comission on Environment and Development. (1987) Report Our commom future. Genebra. Disponível em: <http://www.un-documents.net/wced-ocf.htm.>. Acesso em: jul. 2010.

WWF-Brasil. (2007) Cenários para um Setor Elétrico Eficiente, Seguro e Competitivo. (vol.21, n.59, p. 59-66) Estudos avançados [ online].

Yin, R. K. (1993) Applications of case study research. Califórnia: SAGE Publications. 